\title{
SISTEM PENDUKUNG KEPUTUSAN PEMILIHAN MAHASISWA BERPRESTASI DENGAN METODE FUZZY MULTI-ATTRIBUTE DECISION MAKING SAW
}

\author{
Galih Arizza Candra Aditya Dimas Fatoni Perdana ${ }^{1}$, Rawansyah ${ }^{2}$, Elly Setyo Astuti ${ }^{3}$ \\ ${ }^{1,2}$ Teknik Elektro, Teknik Informatika, Politeknik Negeri Malang \\ 'galiharizza@gmail.com
}

\begin{abstract}
Abstrak
Dalam pemilihan mahasiswa berprestasi, banyak sekali kriteria - kriteria yang harus dipenuhi oleh setiap mahasiswa sebagai syarat dalam pemilihan mahasiswa berprestasi. Untuk membantu dosen dalam menetapkan mahasiswa berprestasi maka dibutuhkan sistem pendukung keputusan. Metode yang digunakan adalah Fuzzy Multi-Attribute Decision Making (FMADM) Simple Additive Weighting (SAW). FMADM SAW sendiri adalah metode dari sistem pendukung keputusan yang menggunakan sistem pembobotan sederhana. Aplikasi ini dirancang dan dikembangkan untuk membantu dosen dalam proses perhitungan pada pemilihan mahasiswa berprestasi di Politeknik Negeri Malang. Berdasarkan hasil uji coba, aplikasi ini dapat membantu proses perhitungan untuk dapat merangking mahasiswa berdasarkan kriteria yang dimiliki masing-masing mahasiswa.
\end{abstract}

Kata Kunci: Kriteria, Pembobotan nilai, FMADM, SAW, alternative, Mahasiswa Berprestasi

\section{Pendahuluan}

Pengambilan keputusan sangat berpengaruh dalam setiap kehidupan manusia. Setiap pengambilan keputusan manusia benar - benar harus menentukan pilihan dari bobot yang jelas dan akurat. Permasalahan pengambilan keputusan juga sering dialami beberapa universitas yang mengadakan pemilihan mahasiswa berprestasi. Karena dalam pemilihan mahasiswa berprestasi memerlukan waktu processing data yang tidak sebentar. Disebabkan karena jumlah mahasiswa yang ada dalam suatu universitas serta kriteria harus benar - benar sesuai dengan ketentuan yang ditetapkan. Seperti IPK, peran organisasi, peran membuat karya ilmiah (PKM), sertifikasi, dan kemampuan berbahasa inggris dengan ketentuan dan bobot yang sudah ada.

Namun proses dalam pemilihan mahasiswa berprestasi di beberapa universitas khususnya pada Politeknik Negeri Malang untuk menentukan bobot dengan perbedaan sertifikat, PKM, peran dalam organisasi masih manual. Data untuk menentukan bobot untuk perbandingan sertifikat, PKM, dan peran dalam organisasi masih belum ditentukan oleh karena itu proses untuk penentuan juara dalam pemilihan mahasiswa berprestasi memerlukan waktu yang tidak singkat.
Dengan teknologi yang dapat diakses dengan cepat oleh juri melalui perangkat keras yang terkoneksi internet, perangkat mobile atau laptop maka akan mempercepat proses penilaian dalam melakukan pemilihan mahasiswa berprestasi serta mempercepat hasil keputusan mahasiswa berprestasi secara cepat dan akurat.

Penghitungan kriteria bobot untuk sertifikat dan PKM secara manual akan membutuhkan banyak waktu untuk prosesnya. Dengan metode Simple Additive Weighting (SAW) yang algoritmanya bisa menentukan nilai alternatif pada setiap kriteria yang diperoleh berdasarkan crips, memberikan nilai bobot berdasarkan crips, melakukan normalisasi matriks, melakukan proses perangkingan, dan menentukan nilai preferensi untk setiap alternatif dapat membantu proses penentuan bobot untuk kriteria tersebut. Untuk itu metode Simple Additive Weighting (SAW) diharapkan cocok digunakan dalam pemilihan mahasiswa berprestasi.

Didukung dengan Sistem Pendukung Keputusan (DSS) di mana sistem ini menyediakan fasilitas untuk melakukan analisis sehingga setiap keputusan proses dibuat berdasarkan kriteria yang ada. Metode yang digunakan dalam penelitian ini adalah dengan menggunakan model Fuzzy MultiAttribute Decision Making (FMADM), Simple 
Additive Weighting Method (SAW). Dengan FMADM SAW ini algoritmanya sangat mudah di implementasikan daripada model FMADM lainnya serta bahwa dalam penelitian sebelumnya FMADM SAW dapat menyelesaikan masalah pemilihan karyawan terbaik. Penelitian ini diharapkan dapat memberikan kemudahan dan efisiensi pengolahan data dalam pemilihan siswa berprestasi serta dapat membantu menentukan hasil atau juara dalam pemilihan mahasiswa berprestasi.

\section{Metode}

Metode Fuzzy SAW untuk pemilihan mahasiswa berprestasi dapat dilihat di gambar 1

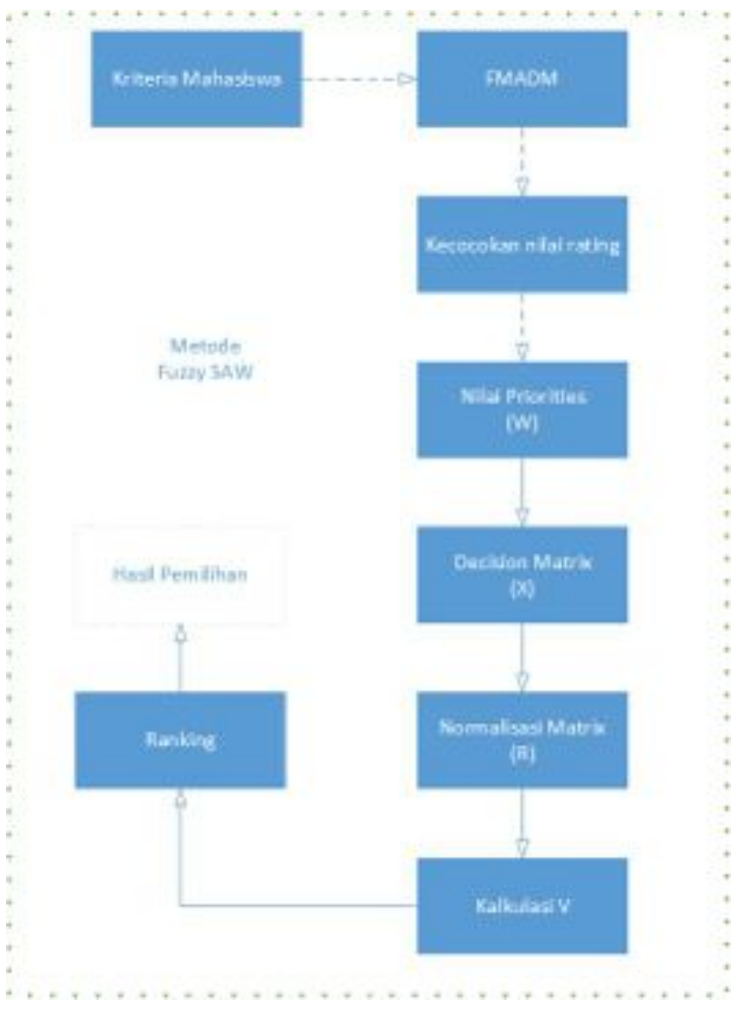

Gambar 1: Gambaran metode FMADM SAW untuk pemilihan mahasiswa berprestasi

\subsection{Fuzzy Multi-Attribute Decision Making (FMADM)}

FMADM adalah metode yang digukanakan untuk mencari alternatif yang optimal dari beberapa alternatif dengan kriteria tertentu. FMADM adalah inti dari penentuan nilai bobot untuk setiap atribut, diikuti dengan proses perangkingan yang akan memilih alternatif yang telah diberikan. Pada dasarnya, ada 3 pendekatan untuk menentukan bobot suatu atribut, yaitu pendekatan subyektif, pendekatan obyektif dan pendekatan integrasi antara subyektif dan obyektif. Masing - masing pendekatan memeiliki kelebihan dan kekurangan. Dalam pendekatan subyektif, bobot ditentukan berdasarkan subyektifitas dari pengambil keputusan, sehingga beberapa faktor dalam peringkat alternatif dapat ditentukan secara independen. Sedangkan pendekatan obyektif, bobot dihitung secara matematis yang mengabaikan subyektivitas dari pengambilan keputusan (Kusumadewi, 2007).

\subsection{Simple Additive Weighting (SAW)}

Metode SAW sering juga dikenal istilah metode penjumlahan terbobot. Konsep dasar metode SAW adalah mencari penjumlahan terbobot dari rating kinerja pada setiap alternative pada semua attribute. Metode SAW membutuhkan proses normalisasi matriks keputusan (x) ke suatu skala yang dapat diperbandingkan dengan semua rating alternatif yang ada.

Salah satu metode penyelesaian masalah MADM adalah dengan menggunakan metode Simple Additive Weighting (SAW). Metode SAW sering juga dikenal istilah metode penjumlahan terbobot. Konsep dasar metode SAW adalah mencari penjumlahan terbobot dari rating kinerja pada setiap alternatif dari semua atribut (Fishburn, 1967). Metode SAW membutuhkan proses normalisasi matriks keputusan (X) ke suatu skala yang dapat diperbandingkan dengan semua rating alternatif yang ada (Kusumadewi, 2006).

Diberikan Persamaan sebagai berikut:

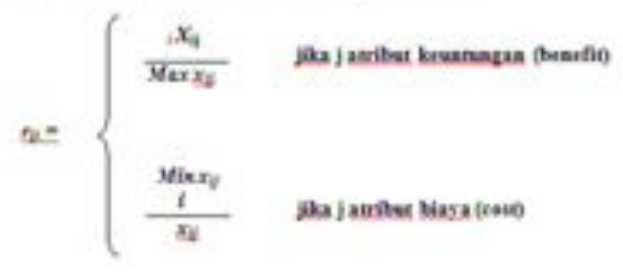

Gambar 2: Persamaan Cost dan Benefit

Dimana rij adalah rating kinerja ternormalisasi dari alternative Ai pada atribut $\mathrm{Cj} ; \mathrm{i}=1,2, \ldots, \mathrm{m}$ dan $\mathrm{j}=1,2, \ldots, n$. Nilai preferensi untuk setiap alternatif (Vi) diberikan sebagai berikut: 


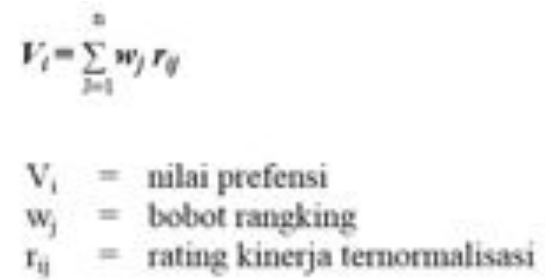

Gambar 3: Persamaan preferensi untuk setiap alternative

Nilai Vi yang lebih besar mengindikasikan bahwa alternative Ai lebih terpilih. Langkah langkah metode SAW adalah (Kusumadewi, 2006):

1. Menentukan kriteria - kriteria yang akan dijadikan acuan dalam pengembalian keputusan, yaitu $\mathrm{C}$.

2. Menentukan rating kecocokan setiap alternative pada setiap kriteria.

3. Membuat matrik keputusan berdasarkan kriteria (C), kemudian melakukan normalisasi matriks berdasarkan persamaan yang disesuaikan dengan jenis atribut (atribut keuntungan ataupun atribut biaya).

4. Hasil akhir diperoleh dari proses perangkingan yaitu penjumlahan dari perangkingan matriks ternormalisasi $\mathrm{R}$ dengan vector bobot sehingga diperoleh nilai terbesar yang dipilih sebagai alternative terbaik (A) sebagai solusi.

\section{Hasil}

Kriteria yang dibutuhkan untuk metode FMADM SAW pemilihan mahasiswa berprestasi bisa dilihat di table 1 .

Tabel 1: Table Kriteria

\begin{tabular}{|c|c|}
\hline No. & Kriteria \\
\hline 1. & IPK \\
\hline 2. & TOEFL Score \\
\hline 3. & $\begin{array}{l}\text { Peran Dalam Organisasi } \\
-\quad \text { Ketua } \\
-\quad \text { Wakil Ketua } \\
-\quad \text { Sekertaris } \\
-\quad \text { Bendahara } \\
-\quad \text { Anggota }\end{array}$ \\
\hline 4. & $\begin{array}{l}\text { Peran Dalam PKM } \\
-\quad \text { Ketua } \\
-\quad \text { Anggota }\end{array}$ \\
\hline 5. & $\begin{array}{cl}\text { Sertifikasi / Piagam } \\
\text { - } & \text { Tingkat Jurusan } \\
\text { - } & \text { Tingkat Politeknik Negeri Malang } \\
\text { - } & \text { Tingkat Nasional }\end{array}$ \\
\hline
\end{tabular}

\begin{tabular}{|l|l|}
\hline & $-\quad$ Tingkat Internasional \\
\hline
\end{tabular}

Dari data kriteria diatas, didefinisikan sebagai pembobotan penilaian prioritas (W) pemilihan mahasiswa berprestasi. Pembobotan terdiri dari 3 bilangan fuzzyyaitu Low (L), Medium (M), High (H). Seperti yang di tunjukan pada gambar 4 .

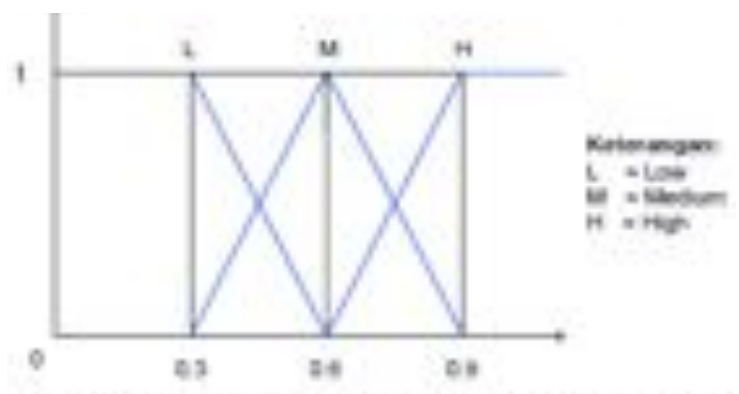

Gambar 4: Fuzzy pada masing - masing kriteria pemilihan mahasiswa berprestasi

Pembobotan untuk masing - masing kriteria pemilihan mahasiswa berprestasi adalah seperti ditampilkan pada table 2 dibawah ini:

Tabel 2: Tabel fuzzy kriteria

\begin{tabular}{|c|c|c|}
\hline $\begin{array}{c}\text { No. } \\
\text { Criteria }\end{array}$ & Fuzzy & Value \\
\hline 1. & High & 0.9 \\
\hline 2. & Medium & 0.6 \\
\hline 3. & Medium & 0.6 \\
\hline 4. & Medium & 0.6 \\
\hline 5. & Low & 0.3 \\
\hline
\end{tabular}

Kriteria No. 1 dan No. 5 terdiri dari 4 bilangan fuzzy yaitu Very Low (VL), Low (L), Medium (M), $\operatorname{High}(\mathrm{H})$.

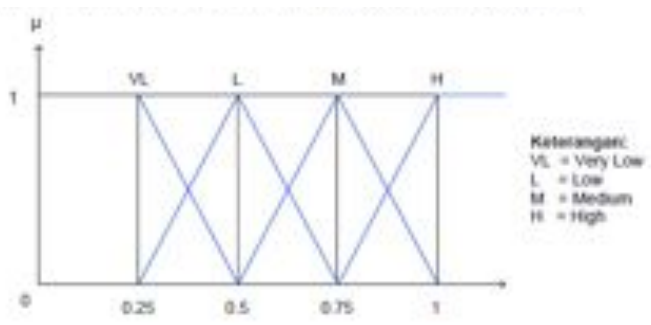

Gambar 5: Fuzzy variable kriteria no 1 dan no 5

Tabel 3: Tabel variabel Fuzzykriteria 1

\begin{tabular}{|c|c|c|}
\hline IPK & Fuzzy & Value \\
\hline IPK $<2.51$ & Very Low & 0.25 \\
\hline IPK 2.51 - 3.00 & Low & 0.5 \\
\hline IPK 3.01 - 3.50 & Medium & 0.75 \\
\hline IPK $>3.50$ & High & 1 \\
\hline
\end{tabular}


Tabel 4: Tabel variabel Fuzzykriteria 5

\begin{tabular}{|c|c|c|}
\hline Sertifikasi/Piagam & Fuzzy & Value \\
\hline Tingkat Jurusan & Very Low & 0.25 \\
\hline $\begin{array}{c}\text { Tingkat Politeknik } \\
\text { Negeri Malang }\end{array}$ & Low & 0.5 \\
\hline Tingkat Nasional & Medium & 0.75 \\
\hline Tingkat Internasional & High & 1 \\
\hline
\end{tabular}

Kriteria No. 2 dan No. 3 mempunyai lima bilangan fuzzyyaitu Very Low (VL), Low (L), Medium (M), High (H), Very High (VH).

Tabel 5: Tabel variabel Fuzzy kriteria No. 2

\begin{tabular}{|c|c|c|}
\hline Toefl Score & Fuzzy & Value \\
\hline TOEFL Score $<311$ & Very Low & 0.2 \\
\hline TOEFL Score $311-420$ & Low & 0.4 \\
\hline TOEFL Score 421- 480 & Medium & 0.6 \\
\hline TOEFL Score 481- 520 & High & 0.8 \\
\hline TOEFL Score $>520$ & Very High & 1 \\
\hline
\end{tabular}

Tabel 6: tabel variabel Fuzzy kriteria No. 3

\begin{tabular}{|c|c|c|}
\hline $\begin{array}{c}\text { Peran Dalam } \\
\text { Organisasi }\end{array}$ & Fuzzy & Value \\
\hline Anggota & Very Low & 0.2 \\
\hline Bendahara & Low & 0.4 \\
\hline Sekertaris & Medium & 0.6 \\
\hline Wakil Ketua & High & 0.8 \\
\hline Ketua & Very High & 1 \\
\hline
\end{tabular}

Dan untuk kriteria yang No. 4 memiliki 2 bilangan Fuzzy yaitu, Low (L) dan High (H).

Tabel 7: Tabel variabel Fuzzy kriteria No. 4

\begin{tabular}{|c|c|c|}
\hline $\begin{array}{c}\text { Peran Dalam } \\
\text { PKM }\end{array}$ & Fuzzy & Value \\
\hline Member & Low & 0.5 \\
\hline Leader & High & 1 \\
\hline & & \\
\hline
\end{tabular}

\section{Pembahasan}

Dari data diatas, dalam tahap pertama untuk perangkingan pemilihan mahasiswa berprestasi bisa dibuat tabel kecocokan nilai rating.

Tabel 8: Tabel Kecocokan nilai rating

\begin{tabular}{|c|c|c|c|c|c|}
\hline \multirow{2}{*}{ Alternative } & \multicolumn{5}{|c|}{ Criteria } \\
\cline { 2 - 6 } & $\mathbf{C 1}$ & $\mathbf{C 2}$ & $\mathbf{C 3}$ & $\mathbf{C 4}$ & $\mathbf{C 5}$ \\
\hline 1. & 0.75 & 0.4 & 0.2 & 0.5 & 0.25 \\
\hline 2. & 0.75 & 0.6 & 1 & 0.5 & 0.5 \\
\hline $\mathbf{3 .}$ & 1 & 0.4 & 0.8 & 0.5 & 0.25 \\
\hline 4. & 0.5 & 1 & 0.2 & 1 & 0.25 \\
\hline $\mathbf{5 .}$ & 1 & 0.8 & 0.2 & 0.5 & 0.25 \\
\hline
\end{tabular}

Setelah ditentukan dalam kecocokan nilai rating, kemudian data di ubah jadi Matrix (X).

$$
X=\left[\begin{array}{ccccc}
0.75 & 0.4 & 0.2 & 0.5 & 0.25 \\
0.75 & 0.6 & 1 & 0.5 & 0.5 \\
1 & 0.4 & 0.8 & 0.5 & 0.25 \\
0.5 & 1 & 0.2 & 1 & 0.25 \\
1 & 0.8 & 0.2 & 0.5 & 0.25
\end{array}\right]
$$

Setelah dijadikan Matrix (X), kemudian dari Matrix (X) di Normalisasikan (R), contoh rumus dari normalisasi adalah sebagai berikut:

$$
R 11=\frac{0.75}{\operatorname{MAX}(0.75 ; 0.75 ; 1 ; 0.5 ; 1)}=\frac{0.75}{1}=0.75
$$

Hasil dari Normalisasi Matrix (R) adalah sebagai berikut:

$$
R=\left[\begin{array}{ccccc}
0.75 & 0.4 & 0.2 & 0.5 & 0.5 \\
0.75 & 0.6 & 1 & 0.5 & 1 \\
1 & 0.4 & 0.8 & 0.5 & 0.5 \\
0.5 & 1 & 0.2 & 1 & 0.5 \\
1 & 0.8 & 0.2 & 0.5 & 0.5
\end{array}\right]
$$

Bobot (W) dari kriteria sudah diketahui sebelumnya pada tabel 2 , maka contoh kalkulasi $\mathrm{V}$ untuk perangkingan:

$$
\begin{aligned}
V 1=(0.75 * 0.9) & +(0.4 * 0.6)+(0.2 * 0.6) \\
& +(0.5 * 0.6)+(0.5 * 0.3) \\
& =1.485
\end{aligned}
$$

Berdasarkan penghitungan menggunakan rumus diatas, maka bisa didapatkan alternative terbaik dari pemilihan mahasiswa berprestasi sebagai pendukung sebagai berikut:

\begin{tabular}{|c|c|c|}
\hline Alternative & $\mathbf{V}$ & Ranking \\
\hline 1 & 1.485 & 5 \\
\hline 2 & 2.235 & 1 \\
\hline 3 & 2.07 & 2 \\
\hline 4 & 1.92 & 4 \\
\hline 5 & 1.95 & 3 \\
\hline
\end{tabular}

\section{Kesimpulan dan Saran}

\subsection{Kesimpulan}

Menurut penelitian sebelumnya, bisa disimpulkan bahwa metode FMADM SAW dapat digunakan untuk pendukung masalah pemilihan karyawan terbaik. Hasil akhir dari metode FMADM yang digunakan dapat digunakan sebagai sistem pendukung pemilihan mahasiswa berprestasi dihasilkan dari hasil perangkingan dari alternatif alternatif. Disamping itu juga algoritma dari SAW 
lebih mudah diimplementasikan dari pada metode FMADM lainnya.

\subsection{Saran}

Untuk menyempurnakan sistem untuk masa mendatang, disarankan untuk:

a. Menampilkan detail laporan perhitungan.

b. Penambahan kriteria

\section{Daftar Rujukan}

Dikti: Panduan Pemilihan Mahasiswa Berprestasi Mawapres Program Diploma, Jakarta 2014

Dikti: Panduan Pemilihan Mahasiswa Berprestasi Mawapres Program Sarjana, Jakarta 2014

Kusumadewi. Sri, Hartati. S, Harjoko. A, and Wardoyo. R: Fuzzy Multi-Attribute Decision Making (FUZZY MADM), Yogyakarta:Graha Ilmu, 2006

Kusumadewi. Sri: Diktat Kuliah Kecerdasan Buatan, Jurusan Teknik Informatika, Fakultas Teknologi Industri Universitas Islam Indonesia, 2007

Kusrini : Konsep dan Aplikasi Sistem Pendukung Keputusan, ANDI, Yogyakarta, 2008.

Turban, Efraim., Aronson, Jay, E., dan Liang, TingPeng : Decision Support Systems and Intelligent Systems, ANDI, Yogyakarta, 2005.

Robandi, Imam : Desain Sistem Tenaga Modern (Optimasi, Logika Fuzzy, Algoritma Genetika), ANDI, Yogyakarta, 2006.

Darmawan, D., Fauzi Nur, Kunkun.: Sistem Informasi Manajemen, PT REMAJA ROSDAKARYA, Bandung, 2013. 